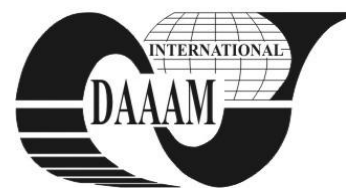

Annals of DAAAM for 2011 \& Proceedings of the 22nd International DAAAM Symposium, Volume 22, No. 1, ISSN 1726-9679 ISBN 978-3-901509-83-4, Editor B. Katalinic, Published by DAAAM International, Vienna, Austria, EU, 2011 Make Harmony between Technology and Nature, and Your Mind will Fly Free as a Bird Annals \& Proceedings of DAAAM International 2011

\title{
BUILDING BUS SYSTEMS COMPARATION
}

\author{
OPLUSTIL, M[ichal]
}

\begin{abstract}
This paper deals with intelligent building communication. System buses are designed for communication in building control networks. This building networks are characterized by short messages, multiple communication media and low bandwidth.There are a many types of system buses on the market.I was picked up two of the open system bus $K N X$ and LON, which are the most common.

Key words: bus, KNX, LON, FSK
\end{abstract}

\section{INTRODUCTION}

In each of the new building we can found building control system. This paper was aim to compare two of the most used building control systems. At first part of paper I describe both systems. At next part of paper I would like to tell some information about data communication of each system bus. In the next phase of research I will try to disclose frequent errors during communication amoung devices on these bus systems. This measuring I on each system will do in laboratory.

\section{LON}

Lonworks is one of leading solution for Building automation. LonWorks and his control protocol named LonTalk was created by Echelon Corporation in 1989 - 1994.

LonWorks was based on Neuron chip. The Neuron chip is the hearth of almost of all LonWorks based devices. The Neuron chip is a complete system on the chip. The Neuron contains the entire LonTalk protocol stack and is comprised of multiple CPU's, memory, I/O, communication port, firmware and operating system.

There are two basic types of Neuron chips, the 3120 and the 3150. Functionally they are similar with the exception of memory configuration and packaging. If memory is not a issue, an application that runs in a 3120 will run in a 3150.Th opposite may not be true if the application is too big for memory size of the 3120 . Basically, the 3120 is a selfcontained unit, all of its memory is onboard and can't be expanded. The 3150 has an external address and data bus to allow expanded memory.

Each Neuron has a 5-pin transceiver interface. The interface is configurable and the parameters are stored in the Comm image.There are three different configurations for the communicationsport:

Single ended Manchester encoded. This is typically used for interfacing to transceivers such as RS485 or Free Topology.

Differential Manchester encoded. This provides a 2-wire polarity independent interface typically found in standard twisted pair wired transceivers. This is the default configuration for the Neuron if nothing else is selected.

Special Purpose Mode. This interface provides a two way port to an intelligent transceiver. Echelon uses this interface with its power line transceivers.
Element addressing perform from hierarchic structure (Domain, Subnet, node); (Domain, Subnet, Neuron_ID);(Domain, Group,Member). Addresss size varies in general while beign invariant with each domain. The size of domain field varies $(0,1,3$ or 6 bytes) ); the subnet and group fields are 8 bits wide, allowing for up to 256 groups and 256 subnets per domain (subnet 0 is reserved value); the size of the node field is 7 bits (an all yeros field not beign used); the size of group member field is 6 bits with range of $0-63$; and the Neuron field is 48 bits wide. Each LonTalk node is assined Unique 48 bit identifier.

For element programming at the LON was used Neuron C programming language which is similar to $\mathrm{C}$ programming language.

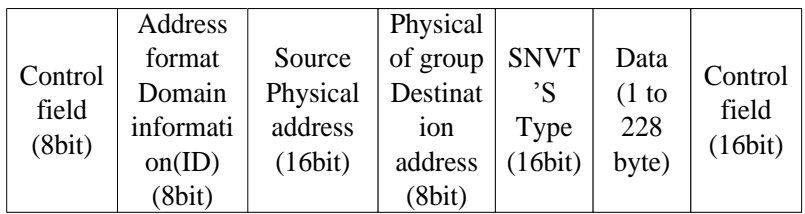

Fig. 1.Lon Telegram

\section{EIB/KNX}

The other type of the open buiding system bus is the EIB/KNX. KNX was developed in 90st. by KNX association. KNX Association contains from EIB, EHS and BatiBus.That is the reason for construction KNX system we can use components from many companies, which carry KNX logo.

KNX system is entirely independent of any specific multiprocessor platform or even architecture. Depending on the profile chosen by the manufacturer, he can select any suitable industry-standard chip, or opt for available KNX OEM solutions like Bus Coupling Units, BIM's, chip sets etc. Some KNX profiles allow a tiny system footprint (say $<5 \mathrm{~kb}$ ),

and easily run on an 8-bit processor. $\mathrm{KNX}$ is a fully distributed network, which accommodates up to 65536 devices in a 16 bit Individual Address space. The logical topology or subnetwork structure allows 256 devices on one line. The lines may be grouped together with a main line into an area. An entire domain is formed by 15 areas together with a backbone line.

The ETS, independent engeneering tool was used for software controlling and configuration of system.

\begin{tabular}{|c|c|c|c|c|c|c|c|}
\hline $\begin{array}{c}\text { Control } \\
\text { field } \\
\text { (8bit) }\end{array}$ & $\begin{array}{c}\text { Source } \\
\text { physical } \\
\text { Address } \\
\text { (16bit) }\end{array}$ & $\begin{array}{l}\text { Phys. of } \\
\text { group } \\
\text { destinatio } \\
\text { n address } \\
\text { (16bit) }\end{array}$ & $\begin{array}{c}\text { Destin. } \\
\text { address } \\
\text { type } \\
\text { (1bit) }\end{array}$ & $\begin{array}{c}\text { Routing } \\
\text { info } \\
\text { (3bit) }\end{array}$ & $\begin{array}{l}\text { Info } \\
\text { lenght } \\
\text { (4bit) }\end{array}$ & $\begin{array}{c}\text { Data } \\
\text { (1 to } \\
16 \\
\text { byte) }\end{array}$ & $\begin{array}{c}\text { Control } \\
\text { field } \\
\text { (8bit) }\end{array}$ \\
\hline
\end{tabular}

Fig. 2. EIB Telegram 


\section{DATA TRANSMISSION}

For data transmission over the bus we use similar type of modulation which is Frequency Shift Keying.

The following table presents difference between LonWorks and KNX systems in this parameters: supported media, maximal bus length between nodes and network speed.

\begin{tabular}{|l|l|l|l|}
\hline $\begin{array}{l}\text { Bus } \\
\text { system }\end{array}$ & $\begin{array}{l}\text { Supported } \\
\text { media }\end{array}$ & $\begin{array}{l}\text { Network } \\
\text { speed }\end{array}$ & $\begin{array}{l}\text { Distance } \\
\text { between nodes }\end{array}$ \\
\hline LON & $\begin{array}{l}\text { PL,TP,IP,RF, } \\
\text { optical }\end{array}$ & $\begin{array}{l}>1 \mathrm{Mbps} \\
\text { (RS485) }\end{array}$ & $\begin{array}{l}\text { Up to } \\
5 \mathrm{~km}(\text { PLT22) }\end{array}$ \\
\hline KNX & PL, TP, RF, IP & $\begin{array}{l}9600 \\
\text { bitps }\end{array}$ & $1 \mathrm{~km}$ \\
\hline
\end{tabular}

Tab. 1. Bus system comparation

\section{FREQUENCY SHIFT KEYING}

The Frequency Shift Kyering is belong to one of the most used digital modulation at high frequency transmission ever.

This was a non-linear modulation with constant envelop. $[s(t)]=$ const . Single unconstant signal parameter is phase. The FSK require that constant frequency at the section and so linear phase at section.

Definition of FSK signal:

$s(t)=A_{s} \sum_{n} \exp \left(j\left(2 \pi d_{n} \frac{\Delta f}{2}(t-n T s)+\varphi\left(d_{n}\right)\right)\right) v_{r e c 1}(t-n T s)$

Where $v_{r e c 1}(t)$ is auxiliary signal type REC1

$$
v_{\operatorname{rec} 1}(t)=\frac{1}{\sqrt{T_{s}}}\left(U(t)-U\left(t-T_{s}\right)\right)
$$

\subsection{Noncoherent Frequency shift keying}

Noncoherent modulation is easier generated than coherent modulation and is usable in many FSK transmittions. This modulation haven't special relation between gradual elements.

\subsection{Coherent Frequency shift keying}

For coherent frequency shift keying modulation is characteristic that, each 1 or 0 bites have equal phase ratio to referential phase. This way we can generate FSK signal by switching between two static frequency oscillators for generate 1 and 0 frequency. When will use this method, transmission is limited on that, we must guarantee variable phase between 1 and 0 , and need that freguency lift and keying would be connected. Coherent FSK was permited better error resistance.

\section{FSK DETECTION}

For equiprobable FSK signaling, the signal has equal energy and the optimal detection rule is given.

$$
\widehat{m}=\arg \max \left|r_{l} * s_{m l}\right|, 1 \leq m \leq M
$$

Assuming that frequency separation between signals id $\Delta f$ the FSK signal have general form:

$$
\begin{gathered}
s_{m}(t)=g(t) \cos (2 \pi(m-1) \Delta f t) \\
=R e\left[g(t) e^{j 2 \pi(m-1) \Delta f t} e^{j 2 \pi f_{c} t}\right], 1 \leq m \leq M
\end{gathered}
$$

Hence, $s_{m l}(t)=g(t) e^{j 2 \pi(m-1) \Delta f t} \quad$ where $g(t)$ is a rectacular pulse of duration $T_{s}$ and $\varepsilon_{g}=2 \varepsilon_{s}$, where $\varepsilon_{s}$ demotes the energy per transitted symbol. At the reciver, the optional noncoherent detector correlates $r_{1}(t)$ with $s_{m l}(t)$ for all $1 \leq m^{\prime} \leq M$. Assuming $s_{m}(t)$ is transmited from

$$
\widehat{m}=\arg \max \left|\int_{-\infty}^{\infty} r_{1}(t) * s_{m l}(t) d t\right|
$$

We have

$$
\begin{gathered}
\widehat{m}=\arg \max \left|\int_{-\infty}^{\infty} r_{1}(t) s_{m l}(t) d t\right| \\
=\mid \int_{-\infty}^{\infty}\left(s_{m l}(t) * n_{l}(t) s_{\dot{m} l}(t) d t \mid\right. \\
=\left|\int_{-\infty}^{\infty} s_{m l}(t) s_{\dot{m} l}(t) d t+\int_{-\infty}^{\infty} n_{l}(t) s_{\dot{m} l}(t) d t\right|
\end{gathered}
$$

This holds for noncoherent detetection

For coherent detection, the detector uses

$$
\widehat{m}=\arg \max \left(\operatorname{Re}\left[\int_{-\infty}^{\infty} r_{l}(t) * s_{\dot{m l}}(t) d l\right]-\frac{1}{2} \int_{-\infty}^{\infty}\left|s_{m l}(t)\right|^{2} d t\right)(7)
$$

And for orthogonality we must have

$$
\operatorname{Re}\left[<s_{m l}(t), s_{\dot{m} l}(t)>\right]=0
$$

\section{CONCLUSION}

In this paper I was taked some information about two of the most used building buses. From my temporary research passes that: LON would be install at large buildings with high count of sensors and actors, for his high network speed and data flow. Contrariwise KNX will find use in smaller installations with less count of sensors and actors.

\section{ACKNOWLEDGEMENTS}

At first of all, I would like to thank my colleaugues from the office for quite working environment. This paper has arisen in the frame of Internal Grant Agency of Tomas Bata University in Zlin, Faculty of Applied Informatics IGA/39/FAI/11/D. Possibilities of testing building control systems.

\section{REFERENCES}

Schneider, W.; Tschischka, W. \& Heinje, T. (2006). Handbook for Home and Building Control, ZVEI-Zentralverband Elektrotechnik- und Elektronikindustrie e. V. German Elektrical and Electronic Manufacturers' Association, Frankfurt am Main

Sauter, T.; Dietrich, D.; Kaster, W.; (Eds.) (2001). EIB Instalation Bus System, Publicis Kommunikations Agentur GmbH GWA Munich, ISBN 3-89578-175-4, Munich

Seip, G.; Hagedorn, K.; Wacker, S.; (1998). Project Engineering for EIB installations, European Installation Bus Association sc Brussels, Brussels

Proakis, J.; Salehi, M.; (2008). Digital communication, McGraw-Hill, a business unit of The Mc Graw-Hill Companies New York, ISBN 978-007-126378-8, New York

Echelon Corporation. (1994). LonTalk protocol specification, Available from: http://www.enerlon.com/JobAids/Lontalk\%20Protocol\%20 Spec.pdf Accessed: 2011-09-01

KNX Association. (2001-2009). KNX system specification, Available from: http://www.sti.uniurb.it/romanell/110504Lez10a-KNX-Architecture\%20v3.0.pdf Accessed: 201109-01 